\title{
Maxillary Gingival Metastasis from Adenocarcinoma Colon
}

\author{
Lekha M Nair ${ }^{1}$, Anitha Mathews ${ }^{2}$, Aparna MP ${ }^{1}$, Sajeed A ${ }^{1}$ \\ Departments of ${ }^{1}$ Radiation Oncology and ${ }^{2}$ Pathology, Regional Cancer Centre, Trivandrum, Kerala, India.
}

\section{Corresponding Author: \\ Dr Lekha M Nair \\ Email: lekhamnair28@gmail.com}

This is an Open Access article distributed under the terms of the Creative Commons Attribution License (creativecommons.org/ licenses/by/3.0).

Received : October 11, 2020

Accepted : March 10,2021

Published : June 10, 2021

\begin{abstract}
Background: Oral cavity metastasis from colorectal cancers is rare. Among these gingival metastases are extremely rare. Few cases of metastasis to mandibular gingiva have been reported. Here we report a rare case of maxillary gingival metastasis from adenocarcinoma colon. Case Report: A fifty-year-old gentleman underwent emergency laparotomy and sigmoid resection for obstructive growth in sigmoid colon and was diagnosed as adenocarcinoma colon, pT4N1. He received twelve cycles of adjuvant chemotherapy. After a disease-free interval of four years, he developed multiple visceral metastases along with an ulcero-proliferative lesion in maxillary gingiva, biopsy from which was reported as adenocarcinoma metastasis from carcinoma colon. He received palliative radiotherapy to the gingival lesion and is on systemic chemotherapy for disseminated disease. Conclusion: Gingiva being a rare metastatic site, a biopsy is warranted to differentiate it from second primary malignancies of oral cavity.
\end{abstract}

Keywords: Adenocarcinoma, Biopsy, Gingiva, Neoplasms, Sigmoid Colon.

\section{Introduction}

Oral cavity forms a rare site of distant metastasis and it forms $1 \%$ of all oral cavity neoplasms [1]. Oral cavity metastasis from colorectal cancers are rare. Most of the metastatic lesions occur in jaw bones [2], but cases of gingival metastasis also have been reported [3-12]. Most of the reported cases of gingival metastases are from mandibular gingiva. Here we report the second case of maxillary gingival metastasis from adenocarcinoma colon.

\section{Case Report}

A fifty-year-old gentleman presented with features of intestinal obstruction. Computed Tomography (CT) scan revealed obstructive growth in sigmoid colon and he underwent emergency laparotomy with sigmoid resection and transverse loop colostomy. Histopathological examination showed moderately differentiated adenocarcinoma, infiltrating serosa with metastasis in lymph node (PT4N1). Metastatic work up showed no evidence of distant metastasis and patient received twelve cycles of adjuvant chemotherapy with modified FOLFOX regimen. After a disease-free interval of four years, he presented with serial rise in CEA values.

PET-CT showed FDG avid lung, liver, adrenal and vertebral metastases. He was started on second line chemotherapy with single agent irinotecan and completed 2 cycles when he presented with a proliferative lesion in the right upper gingiva [Fig.1]. Incision biopsy from the lesion showed moderately differentiated adenocarcinoma, morphologically resembling colonic adenocarcinoma [Fig.2]. Tumor cells were positive for CDX2 and negative for CK7 [Fig.3]. Findings were consistent with metastasis from primary in the sigmoid colon. CT scan showed soft tissue density lesion in maxillary gingiva with underlying bone erosion and progression of lung, liver and adrenal lesions [Fig.4]. Patient received palliative radiotherapy to gingival lesion $30 \mathrm{~Gy}$ in 
10\#, 3Gy per fraction, one fraction per day, five fractions per week over two weeks. The proliferative component decreased after radiotherapy and the size of the lesion remained stable after three months. In view of the disseminated systemic disease, he was started on third line chemotherapy with oral capecitabine and has completed two cycles.

\section{Discussion}

Jaw bones are the common site for metastasis to oral cavity. Metastases to oral soft tissues are rare, gingiva and tongue being the most common sites [1,13-14]. The mechanism of metastasis to gingiva is not known, but proposed mechanism includes hematogenous route. Gingival inflammation is common; the capillaries proliferate and their basement membranes become leaky and makes tumor penetration easy [14].

In the present case, the clinical presentation was an ulcero-proliferative lesion mimicking a second primary in the oral cavity. But biopsy turned out to be adenocarcinoma metastasis from carcinoma colon. Though oral cavity is a rare site of metastasis, all suspicious lesions should be biopsied and metastasis from other primaries should be ruled out. Adenocarcinoma metastatic to the gingiva should be differentiated from primary adenocarcinomas of minor salivary gland origin. Immunohistochemistry may be useful in such situations. Tumor cells of metastatic colonic adenocarcinoma are usually positive for CK 20, CDX2 and CEA and negative for CK7.

Oral cavity metastasis usually occur with other sites of metastasis and prognosis is very bad [3,6-11]. In the present case, the lesion progressed over two weeks and patient developed cheek swelling, pain, bleeding and difficulty in mastication. He was treated with palliative radiotherapy similar to some previously reported cases [10-11]. He had other sites of metastases including lung, liver, adrenals and has been started on systemic therapy also.

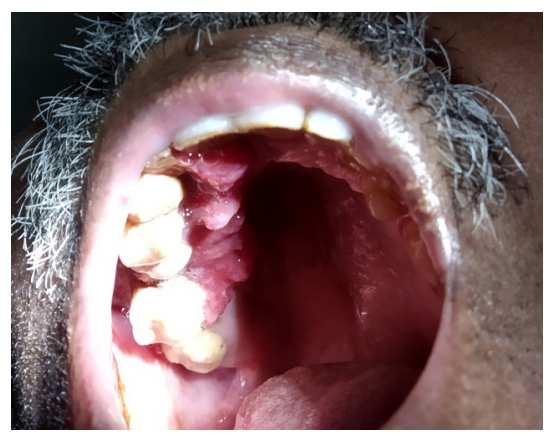

Fig.1: Ulcero-proliferative lesion in right upper gingiva.

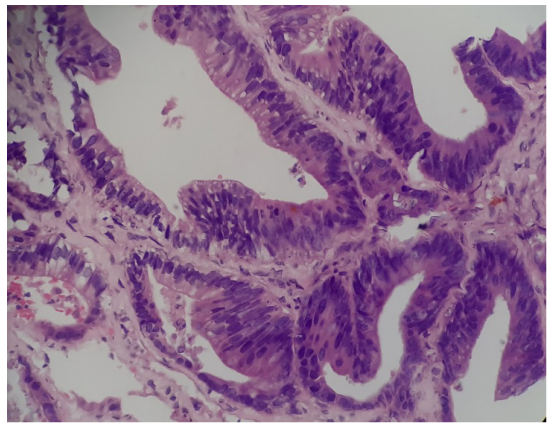

Fig.2: Gingival biopsy: Adenocarcinoma $(H \& E \times 400)$.

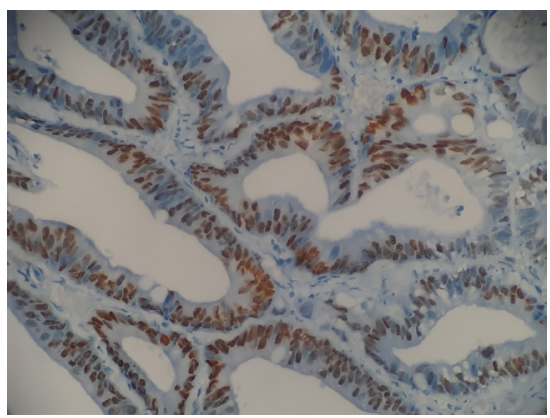

Fig.3: Gingival biopsy: Adenocarcinoma immunostaining for $C D X 2(\times 400)$.

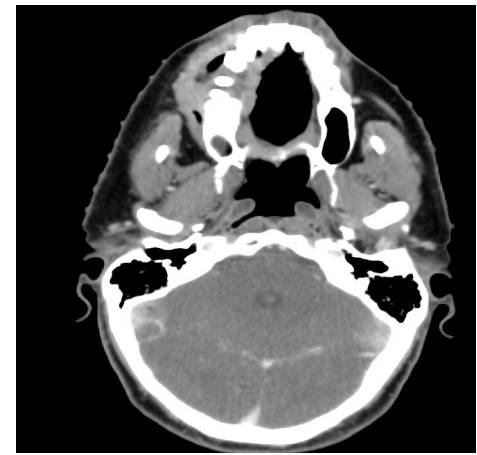

Fig.4: Enhancing soft tissue density lesion in maxillary gingiva with underlying bone erosion. 


\section{Conclusion}

This is the second reported case of maxillary gingival metastasis from carcinoma colon. Index of suspicion is required to identify such rare metastatic sites and should be differentiated from second primary neoplasms. Gingival metastasis usually occurs as part of disseminated metastases and prognosis is poor.

Contributors: LMN: manuscript writing, patient management; AM, AMP: manuscript editing, patient management; AS: critical inputs into the manuscript. LMN will act as a study guarantor. All authors approved the final version of this manuscript and are responsible for all aspects of this study.

Funding: None; Competing interests: None stated.

\section{References}

1. van der Waal RIF, Buter J, van der Waal I. Oral metastases: report of 24 cases. Br J Oral Maxillofac Surg. 2003;41:3-6.

2. Usman N, Kattepur A, Gopinath KS. Metachronous metastasis to the oral cavity from carcinoma rectum a case report and review of literature. Indian Journal of Surgical Oncology. 2014;5(4):303-306.

3. Alvarez-Alvarez C, Iglesias-Rodríguez B, Pazo-Irazu S, Delgado-Sánchez-Gracián C. Colonic adenocarcinoma with metastasis to the gingiva. Med Oral Patol Oral Cirugia Bucal. 2006;11:E85-7.

4. Favia G, Maiorano E, Lo Muzio L. Gingival metastasis from colonic adenocarcinoma. Clin Gastroenterol Hepatol. 2010;8:A28.

5. Soares AB, Thomaz LA, Duarte MT, de Camargo de Moraes P, de Araújo VC. Metastatic adenocarcinoma of the colon: Early manifestation in gingival tissue. Head Neck Pathol. 2011;5:140-143.

6. Lagha A, Chraiet N, Krimi S, Ayadi M, Rifi H, Raies H, Mezlini A. Gingival metastasis from rectal cancer. International Journal of Case Reports and Images. 2012;3(1):24-26.

7. Miyake M, Takebayashi R, Ohbayashi Y, Kushida $\mathrm{Y}$, Matsui Y. Metastasis in the gingiva from colon adenocarcinoma. J Maxillofac Oral Surg. 2015;14(Suppl 1):279-282.

8. Yang RH, Chu YK, Li WY. Unusual site of metastasis detected with FDG PET/CT in a case of recurrent rectosigmoid cancer. Clin Nucl Med. 2014;39:355-357.

9. Baranović M, Vidaković B, Sauerborn D, Perić B, Uljanić I, Mahovne I. Colorectal adenocarcinoma metastasizing to the oral mucosa of the upper jaw. Srpski arhiv za celokupno lekarstvo. 2015;143:314-316.

10. Ren Q-G, Huang T, Yang S-L, Hu J-L. Colon cancer metastasis to the mandibular gingiva with partial occult squamous differentiation: A case report and literature review. Mol Clin Oncol. 2017;6:189-192.

11. Watanabe M, Tada M, Satomi T, Chikazu D, Mizumoto M, Sakurai H. Metastatic rectal adenocarcinoma in the mandibular gingiva: a case report. World J Surg Oncol. 2016;14:199.

12. Pelissari C, Cavalcanti D, Braz-Silva PH, Gallottini M, Trierveiler M. Metastatic colorectal adenocarcinoma in oral cavity: case report and Literature review. J. Oral Diag. 2018;3(1).

13. Hirshberg A, Leibovich P, Buchner A. Metastatic tumors to the jaws: analysis of 390 cases. J Oral Pathol Med.1994;23:337-341.

14. McClure SA, Movahed R, Salama A, Ord RA. Maxillofacial metastases: a retrospective review of one institution 15-year experience. J Oral Maxillofac Surg. 2012;71:178-188. 